\title{
PERBEDAAN PERAWATAN TALI PUSAT TERTUTUP DAN TERBUKA TERHADAP LAMA PELEPASAN TALI PUSAT DI PUSKESMAS SRONDOL DAN PUSKESMAS NGESREP KOTA SEMARANG
}

\author{
Wiwid Ria Trijayanti ${ }^{1}$, Listyaning Eko Martanti ${ }^{2}$, Sri Wahyuni ${ }^{3}$ \\ 1,2,3 Poltekkes Kemenkes Semarang
}

\begin{abstract}
The umbilical cord infection characterize by red, swollen, suppurate, and smelling. This infection can occur treatment that does not hygiene requirements. The treatment uses a frequently replaced sterile gauze pad. Another way to allow an open umbilical cord with clean water and then dried. The goals, know the difference of closed and open umbilical cord care to the umbilical discharge at Srondol Public Health Center and Ngesrep Semarang City. This research is a kind of experiment with posttest only control group design. Population of newborn at Puskesmas Srondol and Ngesrep by purposive sampling technique. Sample 20 was given a closed care and 20 were given an open care. Treatment is measured from 0 days until the umbilical cord is detached by the observation sheet instrument. The results showed that there was a difference of closed and open umbilical cord treatment to the umbilical release length with p.value $=0,000$. The average release time of the open care was 98.7 hours, and the closed care was 170.6 hours. There was a difference of 71.9 hours, so it was concluded that there was a significant difference between closed and open umbilical cord care release of the umbilical cord. It is expected to be notified to health workers to know more effective umbilical cord care to avoid the risk infection.
\end{abstract}

Keywords: open umbilical cord care, closed, release 


\section{PENDAHULUAN}

Pendataan dari Profil Kesehatan

Provinsi Jawa Tengah tahun 2013, jumlah AKB sebanyak 10,41 per 1.000 KH. Pada tahun 2014, jumlah AKB sebanyak 10,08 per $1.000 \mathrm{KH}$. Sedangkan, pendataan pada tahun 2015, jumlah AKB sebanyak 10 per $1.000 \mathrm{KH}$. Maka dapat disimpulkan jumlah AKB dari tahun 2013, 2014 dan 2015 mengalami penurunan. (Dinas Kesehatan Provinsi Jawa Tengah, 2015)

Mayoritas angka kematian neonatus terjadi pada minggu pertama kehidupannya. Penyebab kematian bayi terbanyak adalah prematuritas dan infeksi. Komplikasi ini dapat dicegah dan ditangani dengan pemeriksaan sesuai standar Manajemen Terpadu Bayi Muda (MTBM) dan konseling perawatan bayi baru lahir. (Kemenkes RI, 2015)

Penanganan bayi baru lahir yang lahir yang kurang baik akan menyebabkan kelainan-kelainan yang dapat menyebabkan cacat seumur hidup, bahkan kematian. Salah satunya adalah pencegahan terhadap infeksi yang dapat terjadi melalui tali pusat pada waktu pemotongan tali pusat, melalui mata, melalui telinga pada waktu persalinan atau pada waktu memandikan atau membersihkan bayi dengan bahan yang kurang bersih. (Prawirohardjo S, 2014)
Periode neonatal merupakan periode yang paling kritis dalam fase pertumbuhan dan perkembangan bayi. Tenaga kesehatan terutama bidan penting untuk mengetahui adaptasi fisiologis pada bayi baru lahir karena bidan yang selalu memberikan pelayanan kesehatan bagi ibu, bayi, dan anak. (Dewi, 2010)

Perawatan tali pusat tidak steril dapat mengakibatkan beberapa gangguan kesehatan pada bayi, di antaranya tetanus neonaturum dan omfilitis. (WHO. 2010)

Metode perawatan tali pusat bervariasi. Perawatan tali pusat secara medis menggunakan bahan antiseptik yang meliputi alkohol $70 \%$ atau antimikrobial seperti providone-iodin $10 \%$, dan lain-lain yang disebut cara modern. Sedangkan perawatan tali pusat metode tradisional mempergunakan madu, minyak ghee (India), atau kolostrum ASI. (WHO, 2010)

WHO tidak merekomendasikan pembersihan tali pusat dengan dengan alkohol karena memperlambat penyembuhan dan pengeringan luka. lodin-povidon $10 \%$ merupakan salah satu antimikrobial bersifat bakterisidal melawan bakteri gram positif dan sebagian besar gram negatif. Efeknya mungkin juga dapat menyebabkan reaksi alergi. WHO menyarankan penggunaan antimikrobial sebaiknya tidak secara topikal tidak dilakukan. (WHO, 2010) 
WHO lebih lanjut menjelaskan bahwa aplikasi antimikrobial topikal pada tali pusat masih kontroversi dan hasil dari beberapa penelitian belum dapat disimpulkan apakah aplikasi antimikrobial topikal terbaik dalam menjaga tali pusat tetap bersih. Penggunaannya juga cenderung meningkatkan biaya. Perawatan tali pusat adalah dengan menggunakan pembalut kassa steril yang sering diganti. (Irawan, 2011) Cara lain yaitu dengan membiarkan tali pusat terbuka dan membersihkan luka hanya dengan air bersih. (Dewi, 2010)

Rekomendasi terbaru adalah cukup membersihkan pangkal tali pusat dengan menggunakan air dan sabun, lalu dikeringkan-keringkan hingga benar-benar kering. (WHO, 2010)

Pada umumnya tali pusat akan lepas sendiri setelah mengalami proses nekrosis menjadi kering pada hari ke-6 sampai hari ke-8. (WHO, 2010) Sampai tali pusat menjadi kering dan lepas bisa saja mungkin terjadi infeksi sehingga harus dijaga bersih dan kering. (Bahiyatun, 2009)

Studi pendahuluan yang dilakukan pada tanggal 25 Januari 2018, rerata persalinan tahun 2017 di puskesmas Srondol sebanyak 59 per bulan. Sedangkan persalinan di puskesmas Ngesrep 54 setiap bulannnya. Cakupan KN 2 di wilayah puskesmas Srondol bulan Desember sebanyak 65 , menurun jika dibandingan pada bulan November yakni 51 . Sedangkan KN 2 di wilayah Ngesrep juga mengalami penurunan. Bulan Desember sebanyak 60, dan November 56.

Kebijakan dari puskesmas
Ngesrep sudah sesuai dengan
peraturan terbaru dengan tehnik
terbuka. Namun dalam pelaksanaannya tidak semua ibu bersedia melakukan perawatan tali pusat terbuka. Rasa ketidaknyamanan ibu terhadap bayinya menjadi alasan utama. Mereka beranggapan teknik terbuka justru menimbulkan infeksi dan lama puputnya. Maka ibu cenderung menutup tali pusat bayinya dengan kassa dari bidan praktik mandiri. Lama puputnya tali pusat di wilayah tersebut berkisar 6-7 hari dan dua bayi yang puputnya 8 hari.

Meskipun tidak ditemukan kejadian infeksi tali pusat, petugas tenaga kesehatan tetap harus melakukan program kunjungan neonatal dengan benar agar terhindar dari resiko infeksi. Dua fungsi tali pusat. Pertama, sebagai saluran yang menghubungkan antara plasenta dan bagian tubuh janin sehingga janin mendapat asupan oksigen. Kedua, sebagai saluran pertukaran bahan sisa seperti urea dan gas karbon dioksida yang akan meresap keluar melalui pembuluh darah arteri umbilicalis. (Baety, 2011) Lepasnya tali pusat dipengaruhi oleh beberapa faktor. (Prawirohardjo , 2014) 
1) Cara perawatan tali pusat.

2) Timbulnya infeksi.

3) Kelembaban tali pusat.

4) Kondisi sanitasi lingkungan.

Selain infeksi, perdarahan pada tali pusat juga dapat berakibat fatal. Akan tetapi perdarahan dapat dicegah dengan melakukan penjepitan tali pusat dengan kuat dan pencegahan infeksi. Prinsip perawatan tali pusat adalah perlu dijaga kebersihannya. (Irawan, 2011)

Anjuran Kemenkes RI bahwa tindakan pada bayi baru lahir meliputi. (Kemenkes RI. 2015)

1) Menjaga kebersihan selama persalinan

2) Mencegah infeksi kuman pada bayi. Setelah bayi lahir, perawat memberi salep antibiotik pada mata bayi

3) Menjaga tali pusat selalu bersih, kering, dan biarkan terbuka (jangan dibungkus)

4) Jangan memberikan ramuan apapun. Jika kotor, bersihkan dengan kain bersih dan air matang.

Berikut langkah - langkah perawatan tali pusat terbuka :

1) Cuci tangan dengan air bersih dan sabun sampai bersih.

2) Cuci tali pusat dengan air matang secara hati-hati.

3) Bila tali pusat terkena kotoran/tinja cuci dengan sabun kemudian bilas dan keringkan sampai kering dengan waslap atau handuk kering yang lembut.

4) Biarkan tali pusat dalam keadaan terbuka agar terkena udara.

5) Lipatlah popok dibawah tali pusat.

6) Kenakan pakaian bayi.

7) Cuci tangan kembali setelah membersihkan tali pusat. Tali pusat harus dibersihkan sedikitnya dua kali dalam sehari.

Selama tali pusatnya belum puput, sebaiknya bayi tidak dimandikan dengan cara dicelupkan ke dalam air. Bayi cukup dimandikan dengan dilap saja dengan air hangat agar tali pusat tetap kering. Bagian yang harus dibersihkan yaitu pangkal tali pusat bukan atasnya. Cara membersihkan pangkal ini harus sedikit mengangkat (bukan menarik tali pusat). Sisa air yang menempel pada tali pusat dapat dikeringkan dengan kain kassa steril atau kapas, setelah itu tali pusat dikeringkan. (Simsin Penny, 2017)

\section{METODOLOGI PENELITIAN}

Penelitian ini merupakan jenis experiment dengan desain posttest only control group. Dengan populasi bayi baru lahir di Puskesmas Srondol dan Puskesmas Ngesrep. Pengambilan sampel yakni teknik purposif sampling. Purposive sampling adalah cara pengambilan sampel untuk tujuan tertentu. (Hidayat AAA, 2014.) 
Sampel penelitian berjumlah 20 untuk kelompok kontrol yang diberi intervensi metode perawatan tertutup dan 20 untuk kelompok perlakuan yang diberi intervensi metode perawatan terbuka. Perawatan tali pusat diukur mulai dari 0 hari sampai tali pusat terlepas. Instrument yang digunakan adalah lembar observasi.

Pengumpulan data menggunakan data primer dan data sekunder melalui lembar observasi, pelaksanaan langsung datang ke responden dengan bantuan 4 orang enumerator pada tanggal 1 April-18 Mei 2018 di puskesmas Srondol dan puskesmas Ngesrep, Banyumanik, Semarang.

Ethical Clearance didapatkan dari Komisi Etik Penelitian Kesehatan (K.E.P.K) Politknik Kesehatan Kemenkes Semarang dengan nomor : 320/KEPK/PoltekkesSmg/EC/2018.

Analisa data menggunakan uji normalitas dan homogenitas data, dan uji independent test.

\section{HASIL PENELITIAN DAN BAHASAN}

Tabel karakteristik dibawah ini memaparkan data karakteristik responden dilihat dari usia kehamilan, usia ibu, paritas, berat bayi lahir dan jenis kelamin bayi.
Tabel 1.Karakteristik Responden

\begin{tabular}{llll}
\hline KarakteristikResponen & $\begin{array}{l}\text { Metode } \\
\text { Terbuka } \\
(\%)\end{array}$ & $\begin{array}{l}\text { Metode } \\
\text { Tertutup } \\
(\%)\end{array}$ \\
\hline Usia & $<38$ & 0 & 0 \\
Kehamilan & $38-40$ & 100 & 100 \\
& $>40$ & 0 & 0 \\
& Total & 100 & 100 \\
\hline Usia ibu & $<20$ & 5 & 10 \\
& $20-35$ & 80 & 85 \\
& $>35$ & 15 & 5 \\
& Total & 100 & 100 \\
\hline Paritas & Primipara & 55 & 65 \\
& Multipara & 45 & 35 \\
& Total & 100 & 100 \\
\hline Berat & Bayi<2500 & 0 & 0 \\
Lahir & $2500-4000$ & 100 & 100 \\
& $>4000$ & 0 & 0 \\
& Total & 100 & 100 \\
\hline Jenis & Laki & 35 & 50 \\
Kelamin & Perempuan & 65 & 50 \\
& Total & 100 & 100 \\
\hline
\end{tabular}

Berdasarkan tabel 1 karakteristik responden, karakteristik usia kehamilan ibu untuk metode terbuka menunjukkan semua kehamilan ibu sudah memasuki kehamilan aterm (100\%), demikian juga usia kehamilan ibu untuk metode tertutup semua juga sudah memasuki kehamilan aterm (100\%).

Karakteristik berdasarkan usia ibu untuk metode terbuka, ibu yang berumur 20-35 tahun sebanyak 16 orang (80\%), berumur $<20$ tahun terdapat 1 orang $(5 \%)$, dan berumur $>35$ tahun sebanyak 3 orang (15\%). Karakteristik berdasarkan usia ibu untuk metode tertutup, ibu yang berumur 20-35 tahun sebanyak 17 orang (85\%), berumur $<20$ tahun terdapat 2 orang (10\%), dan ibu yang berumur $>35$ tahun ada 1 orang (5\%). 
Karakteristik berdasarkan paritas untuk metode terbuka, ibu yang tergolong primipara sejumlah 11 orang (55\%), dan sisanya berjumlah 9 orang (45\%) tergolong multipara. Sedangkan karakteristik berdasarkan paritas untuk metode tertutup, ibu yang tergolong yang primipara sebanyak 13 orang (65\%), dan sisanya 7 orang (35\%) ibu yang tergolong multipara Karakteristik berat badan lahir bayi untuk metode terbuka semua sudah memenuhi kriteria berat badan lahir normal (100\%). Demikian juga untuk metode tertutup yakni (100\%).

Karakteristik jenis kelamin untuk metode terbuka yang bejenis kelamin lakilaki sebanyak 7 orang (35\%), dan 13 orang $(65 \%)$ yang berjenis kelamin perempuan. Sedangkan metode tertutup yang berjenis kelamin laki-laki sebanyak 10 orang (50\%) dan 10 orang $(50 \%)$ yang berjenis kelamin perempuan.

Tabel 2. Lama Waktu Pelepasan Tali Pusat dengan Metode Terbuka dan Tertutup

\begin{tabular}{llll}
\hline Variabel & \multicolumn{3}{c}{ Metode Terbuka Metode Tertutup } \\
\hline $\mathrm{N}$ & 20 & 20 & \\
Min & 90 & 164 & \\
Max & 109 & 177 & \\
Mean & 98,7 & 170,6 & \\
SD & 3,67 & 3,26 & \\
Varians & 13,48 & 10,67 & \\
\hline \multicolumn{5}{r}{ Berdasarkan } & tabel 2. diatas
\end{tabular}

menunjukkan bahwa nilai rata-rata lama waktu pelepasan tali pusat yang diberikan intervensi perawatan tali pusat dengan metode terbuka adalah 98,7 jam (4 hari 2,7 jam), waktu pelepasan tali pusat tercepat adalah 90 jam (3 hari 18 jam), waktu pelepasan tali pusat terlama adalah 109 jam (4 hari 13 jam).

Sedangkan nilai rata-rata lama waktu pelepasan tali pusat yang diberikan intervensi perawatan tali pusat dengan metode tertutup adalah 170,6 jam (7 hari 2,6 jam), waktu pelepasan tali pusat tercepat adalah 164 jam (6 hari 20 jam), dan waktu pelepasan tali pusat terlama adalah 177 jam (7 hari 9 jam).

Tabel 3. Uji Beda lama waktu pelepasan tali pusat setelah diberikan intervensi perawatan tali pusat tertutup dan terbuka.

\begin{tabular}{ll}
\hline Variabel & Metode Metode Mean $P$ Value \\
& Tertutu Terbuka Differenc \\
& $p \quad$ (Mean) e \\
& (Mean)
\end{tabular}

\begin{tabular}{llll}
\hline LamaWaktu 170,6 & 98,7 & 71,9 & 0,000
\end{tabular} (jam)

Berdasarkan tabel 3, didapatkan hasil perhitungan statistik mengunakan uji independent t-test yang dapat dilihat bahwa nilai $p$ value yaitu $0,000<0,05$. Yang berarti Ho ditolak dan Ha diterima sehingga terdapat perbedaan yang signifikan antara lama waktu pelepasan tali pusat kelompok perawatan tali pusat terbuka dan tertutup.

Lama waktu pelepasan tali pusat dengan metode terbuka lebih cepat yaitu 98,7 jam dan lama waktu pelepasan tali pusat untuk metde tertutup 170,6 jam. Selisih waktu lama pelepasan tali pusat antara metode terbuka dan tertutup 71,9 jam.

Karakteristik umur responden sebagian besar berumur 20-35 tahun yaitu 
16 orang $(80 \%)$ untuk perawatan terbuka dan 17 orang (85\%) untuk perawatan tertutup. Hampir seluruh responden melahirkan sudah di usia reproduksi sehat. Umur reproduksi sehat adalah umur yang aman untuk kehamilan dan persalinan yaitu berumur 20-35 tahun. Umur dibawah 20 tahun, keadaan alat reproduksi belum siap untuk menerima kehamilan dikarenakan organ reproduksi belum matang. Kehamilan dibawah umur 20 tahun merupakan kehamilan berisiko tinggi. (Cunningham, 2005)

Apabila umur ibu saat hamil diatas 35 tahun, keadaan organ reproduksi tidak begitu berfungsi dengan baik seperti sebelumnya karena ada perubahan jaringan dan alat kandungan sehingga tidak lentur lagi. Kehamilan diatas umur 35 tahun mempunyai problem kesehatan seperti hipertensi, diabetes mellitus, anemia, dan penyakit kronis lainnya sehingga tidak dianjurkan memiliki kehamilan diatas umur 35 tahun. (Siswosudarmo, R. 2008) Selain itu, umur ibu erat kaitannya dengan pengetahuan yang dimiliki. Umur merupakan variabel yang sangat penting dalam mempengaruhi pengetahuan. Semakin tinggi umur seseorang semakin bertambah pula ilmu dan pengetahuan seseorang.

Usia kehamilan ibu menunjukkan seluruh responden sudah memasuki usia kehamilan aterm yaitu 38-40 minggu $(100 \%)$, baik perawatan terbuka dan tertutup. Berdasarkan penelitian Ira, bahwa infeksi tali pusat memiliki hubungan bermakna dengan kejadian ketuban pecah $\operatorname{dini}(K P D)$.

Selaput ketuban yang utuh merupakan barier atau penghalang terhadap masuknya penyebab suatu infeksi. Dengan tidak adanya selaput ketuban seperti pada KPD, flora vagina yang normal bisa menjadi patogen yang akan membahayakan ibu maupun janinnya. Kejadian KPD berkisar antara 8 $10 \%$ dari semua kehamilan dan lebih banyak terjadi pada kehamilan cukup bulan (sekitar 95\%), sedangkan pada kehamilan kehamilan preterm terjadi sekitar 34\%. (Siswosudarmo, R. 2008.)

Data paritas ibu menunjukkan hasil untuk kelompok perawatan tali pusat dengan metode terbuka yang tergolong primipara sebanyak 11 orang (55\%), sedangkan sisanya sejumlah 9 orang (45\%) adalah ibu yang tergolong multipara. Kelompok perawatan tali pusat dengan metode tertutup yang tergolong primipara sebanyak 13 orang (65\%), dan sisanya sejumlah 7 orang (35\%) adalah ibu yang tergolong multipara.

Data paritas berhubungan dengan cara penerimaan ibu. Semakin banyak pengalaman ibu maka penerimaan ibu semakin mudah dalam kemampuan merawat bayinya. Pengalaman ibu diperoleh dari lingkungan sosial. Lingkungan sosial yang baik akan memberikan pengetahuan yang baik pula. Semakin sering kegiatan di lingkungan 
sosial dilakukan maka semakin banyak informasi yang bisa digali dan diperoleh ibu. Semakin banyak pengalaman dan pengetahuan atau informasi ibu. Ibu telah belajar tentang sesuatu yang telah dilewati dan dari pembelajaran yang diterima, pengetahuan ibu berubah dan bertambah. Dengan demikian ibu dengan paritas lebih dari satu kali, pengalaman ibu lebih banyak sehingga memiliki kemampuan merawat bayi lebih baik. Berdasarkan karakteristik berat badan lahir bayi menunjukkan hasil semua responden memenuhi kriteria berat badan lahir normal (100\%), baik untuk perawatan terbuka maupun tertutup.

Penelitian yang dilakukan Ira menunjukkan berat badan lahir memiliki hubungan bermakna dengan kejadian infeksi tali pusat. Bayi dengan berat badan lahir rendah memiliki risiko terinfeksi bakteri karena fungsi dan anatomi kulit yang masih imatur dan lemahnya sistem imun. Prajoga berpendapat bahwa bayi dengan BBLR kemungkinan untuk meninggal pada masa neonatal 20-30 kali dan 17 kali lebih besar sebelum usia satu tahun daripada bayi yang dilahirkan dengan berat badan lahir normal. (Siswosudarmo, R. 2008) Dalam penelitian ini berat badan lahir bayi tidak berpengaruh terhadap hasil penelitian karena semua bayi memiliki berat badan lahir normal.

Berdasarkan jenis kelamin menunjukkan hasil untuk kelompok perawatan dengan metode terbuka, responden yang berjenis kelamin laki-laki sebanyak 7 orang (35\%), sedangkan sisanya sejumlah 13 orang (65\%) yang berjenis kelamin perempuan. Sedangkan untuk kelompok perawatan dengan metode tertutup, responden yang berjenis kelamin laki-laki sebanyak 10 orang (50\%), sedangkan sisanya sejumlah 10 orang (50\%) yang berjenis kelamin perempuan. Jenis kelamin bayi pada penelitian ini tidak berpengaruh terhadap kejadian infeksi tali pusat pada bayi.

Hasil analisis univariat menunjukkan bahwa waktu tercepat yang dimiliki perawatan terbuka adalah 90 jam (3 hari 18 jam), dan waktu terlama adalah 109 jam (4 hari 13 jam). Menurut Cunningham (2013), tali pusat yang dirawat dengan cara dibiarkan terbuka akan lebih cepat kering dan puput sehingga meminimalisir risiko terjadinya infeksi.

Tali pusat yang terbuka akan banyak terpapar dengan udara luar sehingga air dan wharton's jelly yang terdapat di dalam tali pusat akan lebih cepat menguap sehingga dapat mempercepat proses pengeringan (gangrene) tali pusat sehingga tali pusat cepat terlepas. (Prawirohardjo S, 2014)

Berdasarkan penelitian Nor Aisyah menyatakan bahwa perawatan tali pusat dengan metode terbuka lebih efektif dalam upaya mempercepat pelepasan tali pusat. Hal ini telah terbukti tali pusat lebih cepat puput yaitu dengan hasil analisa tabel diatas didapat waktu tercepat 90 jam (3 hari 18 jam), dan waktu terlamanya adalah 
109 jam (4 hari 13 jam) bahkan lebih cepat dibandingkan waktu tercepat metode perawatan tertutup yaitu 164 jam (6 hari 20 jam). (Prawirohardjo S, 2010)

Lama pelepasan tali pusat dengan menggunakan metode perawatan tali pusat tertutup tercepat adalah 164 jam (6 hari 20 jam), dan waktu terlama adalah 177 jam (7 hari 9 jam). Perawatan tali pusat tertutup adalah perawatan tali pusat dengan cara menutupnya dengan pembalut kassa kering atau steril tanpa dibubuhi apapun. (Kemenkes RI, 2014)

Hasil analisis bivariat menunjukkan bahwa berdasarkan lama waktu pelepasan tali pusat dengan menggunakan metode perawatan terbuka dan tertutup adalah rata-rata metode terbuka adalah adalah 98,7 jam (4 hari 2,7 jam), rata-rata metode perawatan tali pusat tertutup adalah 170,6 jam (7 hari 2,6 jam). Hal ini dikarenakan tali pusat yang dirawat dengan teknik dibiarkan terbuka akan lebih cepat kering.

Berdasarkan teori dan hasil analisis diatas waktu rata-rata pelepasan tali pusat metode tertutup adalah 170,6 jam (7 hari 2,6 jam) karena metode tertutup tidak menurunkan kolonisasi bakteri. Jadi, lama waktu pelepasan tali pusat terjadi lebih lama dibandingkan yang menggunakan metode terbuka yakni 98,7 jam (4 hari 2,7 jam) dimana terdapat selisih 71,9 jam (2 hari 23,9 jam). Hal ini terjadi karena dipengaruhi oleh faktor kelembaban dan kebersihan saat perawatan.
Hal ini sesuai dengan teori Saifuddin, tali pusat tidak boleh ditutup rapat dengan apapun, karena akan membuatnya menjadi lembab. Perawatan tali pusat yang tidak baik justru akan menyebabkan tali pusat menjadi terlepas lama. Selain memperlambat puputnya tali pusat juga menimbulkan resiko infeksi tali pusat dan Tetanus Neonatus (TN). (Sodikin, 2009)

$$
\text { Hasil waktu tercepat perawatan tali }
$$

pusat dengan metode terbuka dibandingkan metode tertutup yaitu 90 jam (3 hari 18 jam). Hal ini dikarenakan tali pusat yang dirawat dengan teknik dibiarkan terbuka akan lebih cepat kering. Tali pusat yang terbuka lebih banyak terpapar dengan udara luar sehingga air dan wharton's jelly yang terdapat di dalam tali pusat akan lebih cepat menguap sehingga dapat mempercepat proses pengeringan tali pusat sehingga lebih cepat terlepas asalkan cara perawatannya dilakukan dengan tepat dan sesuai prosedur.

Waktu terlama perawatan tali pusat dengan metode terbuka dibandingkan perawatan metode tertutup yaitu 109 jam (4 hari 13 jam). Kondisi ini dikarenakan dipengaruhi oleh faktor kelembaban dan kebersihan saat perawatan yang baik.

Hasil waktu tercepat perawatan tali pusat dengan metode perawatan tertutup dibandingkan dengan metode perawatan terbuka yaitu 164 jam (6 hari 20 jam). Keadaan ini dipengaruhi oleh faktor cara 
perawatan yang sesuai dengan prosedur, kelembaban dan kebersihan tali pusat yang baik, dan tidak adanya infeksi.

Hal ini sesuai dengan teori Prawirohardjo, Lepasnya tali pusat dipengerahui oleh beberapa hal ,diantaranya : 1) Cara perawatan tali pusat. 2) Timbulnya infeksi. 3) Kelembaban tali pusat. 4) Kondisi sanitasi lingkungan. (Riksani, Ria. 2012)

Hasil penelitian menunjukkan bahwa ada perbedaan lama waktu pelepasan tali pusat setelah diberikan intervensi perawatan tali pusat dengan metode tertutup dan terbuka. Nilai taraf signifikan atau $0.000<0.05$ maka $\mathrm{HO}$ ditolak. Karena HO ditolak, maka dapat disimpulkan bahwa ada perbedaan antara perawatan tali pusat dengan metode tertutup dan perawatan tali pusat dengan metode terbuka terhadap lama pelepasan tali pusat.

Berdasarkan hasil perhitungan tersebut menunjukkan bahwa kelompok perawatan tali pusat dengan metode terbuka memiliki peluang untuk mempercepat lama waktu pelepasan tali pusat dibandingkan dengan kelompok perawatan tali pusat dengan metode tertutup.

\section{KESIMPULAN}

Rata-rata lama waktu pelepasan tali pusat dengan metode perawatan tali pusat terbuka adalah 98,7 jam (4 hari 2,7 jam), sedangkan untuk perawatan tali pusat tertutup adalah 170,6 jam (7 hari 2,6 jam). Lama pelepasan tali pusat dengan intervensi metode terbuka lebih cepat dibandingkan dengan metode tertutup. Dimana waktu tercepat yang dimiliki perawatan terbuka 90 jam (3 hari 18 jam), sedangkan perawatan tertutup 164 jam (6 hari 20 jam). Terdapat perbedaan lama waktu pelepasan tali pusat antara perawatan dengan metode terbuka dibandingkan dengan metode tertutup yaitu terdapat selisih 71,9 jam (2 hari 23,9 jam). Diharapkan ibu dapat menambah pengetahuan terbaru mengenai perawatan tali pusat terbuka sehingga ibu dan keluarga dapat mempraktikkan perawatan tali pusat pada bayi baru lahir dengan metode terbaru

\section{DAFTAR PUSTAKA}

1. Baety, A. N. 2011. Asuhan Kebidanan Pada masa Kehamilan. Jakarta: Salemba Medika.

2. Bahiyatun.2009. Buu Ajar Asuhan Kebidanan Nifas Normal. Jakarta: EGC .

3. Cuningham, FG., et al,2013. Obstetri Williams Jakarta: EGC.

4. Cunningham. 2005. Williams Obstetrics 21st. USA: The Mc Graw Hill Companies, Inc.

5. Dewi, VN. 2010. Asuhan Neonatus Bayi dan Anak Balita. Jakarta : Salemba Medika. 
6. Dinas Kesehatan Provinsi Jawa Tengah. 2015. Profil Kesehatan Provinsi Jawa Tengah. Semarang : Dinkes Provinsi Jateng.

7. Hidayat AAA. 2014. Metode Penelitian Kebidanan Dan Teknik Analisis Data. Jakarta: Salemba Medika.

8. Irawan, N.K. 2011. Menumpas Penyakit dengan Darah Tali Pusat. Jakarta : Berlian Medika.

9. Kemenkes RI. 2014. Profil Kesehatan Indonesia. Jakarta : Kementrian Kesehatan Republik Indonesia.

10. Kemenkes RI. 2015. Profil Kesehatan Indonesia. Jakarta: Kementrian Kesehatan Republik Indonesia.

11. Nor Asiyah, Islami, dan Lailatul M. 2017. Perawatan Tali Pusat Terbuka Sebagai Upaya Memper- cepat Pelepasan Tali Pusat. Jurnal Kebidanan. Vol. I No.I

12. Prawirohardjo S. 2010. Buku Acuan Pelayaanan Kesehatan Maternal Dan Neonatal. Jakarta : PT Bina Pustaka.

13. Prawirohardjo S. 2014. Buku Acuan Pelayaanan Kesehatan Maternal Dan Neonatal. Jakarta : PT Bina Pustaka.

14. Riksani, Ria. 2012. Keajaiban ASI (Air Susu lbu), jAkarta Timur: Dunia Sehat. 15. Sartrawinata Sulaiman. 1983. Obstetri Patologi: Ilmu Kesehatan Reproduksi. Jakarta: EGC.

16. Sodikin. 2009. Buku Saku Manajemen Masalah Bayi Baru Lahir Panduan untuk Dokter, Perawat \& Bidan. Jakarta: ECG.
17. Saifuddin, A. 2009. Buku Acuan Nasional Pelayanan Kesehatan Maternal Neonatal. Jakarta: YBPSP.

18. Simsin Penny. 2017. Panduan Lengkap Kehamilan Melahirkan dan Bayi. Jakarta:Archan

19. Siswosudarmo, R. 2008. Obstetri Fisiologi. Yogyakarta: Pustaka Cendekia.

20. WHO. 2010. Care of the umbilical cord : A review of the evidence. Terdapat pada www.who.int/csr/disease/swineflu/en/i ndex.html. Diakses pada : 13 Oktober 2017. 